\title{
GIANT CONGENITAL MELANOCYTIC NEVUS (BATHING TRUNK NEVUS)- A CASE STUDY
}

\author{
Jonnalagadda Balachandrudu¹, Beri Udaya Kumar²
}

${ }_{1}^{1}$ Assistant Professor, Department of Dermato-Venereology, Sri Venkateswara Medical College/ SVRRGG Hospital, Tirupati, A. P. 2Professor, Department of Dermato-Venereology, Kurnool Medical College/ Government General Hospital, Kurnool, A. P.

HOW TO CITE THIS ARTICLE: Balachandrudu J, Kumar BU. Giant congenital melanocytic nevus (bathing trunk nevus)- a case study. J. Evolution Med. Dent. Sci. 2018;7(13):1681-1683, DOI: 10.14260/jemds/2018/380

\section{PRESENTATION OF CASE}

A thirteen-years-old female child presented to our Dermatology Department, had a large circumferentially pigmented area in front of neck, spread to chest, abdomen to thighs and up to knees as well as same spread to back of body bilaterally, interposed darkened lesions were present. Born by normal delivery to non-consanguineous parents presented with an asymptomatic hyperpigmented encompassing the entire trunk involving chest, back, buttocks and genitalia covering more than $40 \%$ of body area present since birth. It has been growing in size with age. The lesions were flat initially and gradually started becoming thicker. Scalp, mucosa, palms, soles and nails were normal.

There were no signs of jaundice, haemolysis, meningomyelocele or abnormal hair growth. The rest of the physical examination including cardiovascular, pulmonary and abdominal system and genitourinary functioning was normal. Complete blood picture was within normal range. There was immediate concern of melanoma by Paediatric Dermatology and General Surgery physicians.

Magnetic resonance imaging of the lumbar spine and brain revealed no intracranial abnormalities, hydrocephalus or suggestion of meningeal inflammation.

Giant congenital melanocytic nevi are rare and occur in about one out of every 2,00,000 to 5,00,000 births. There is a significant association between bathing trunk nevus and neurofibromatosis and lipomatosis. Apart from this association of bathing trunk nevus with abnormalities like spina bifida occulta, meningocoele, club foot and hypertrophy or atrophy of deeper structures of a limb have been described.

Biopsy report showed skin with groups of nevoid cells extending into underlying fat, intimately associated with the lobules and surrounding many blood vessels. Pathologic examination revealed benign congenital intradermal nevus without evidence of malignancy. The systemic examination was normal. This is a typical case of giant congenital melanocytic nevus. As the surface area is greater than $50 \mathrm{~cm}$ in diameter, the risk of developing melanoma is higher.[1]

Congenital melanocytic nevus is a benign neoplasm composed of naevomelanocytes, which occurs in about $1 \%$ to $2 \%$ of new-borns. Giant congenital melanocytic nevus is a variant of congenital melanocytic nevus, characterised by its extensive size and is defined as melanocytic nevus measuring

'Financial or Other Competing Interest': None.

Submission 17-02-2018, Peer Review 10-03-2018,

Acceptance 19-03-2018, Published 26-03-2018.

Corresponding Author:

Dr. Jonnalagadda Balachandrudu,

Mullapudi Enclave, Flat No. 204,

Opp. KKR Plaza, $3^{\text {rd Line, Kannavarithota }}$

Guntur-522004, A. P.

E-mail: jonnalagaddabalu@gmail.com

DOI: $10.14260 /$ jemds/2018/380

(c) (i) $(9)$ more than $20 \mathrm{~cm}$ in its great dimension with a female predominance. These giant nevi often have a garment-like distribution. They are usually deeply pigmented, covered with moderate growth of hair and often there are many scattered satellite lesions associated with them. The hairy component which occurs in $95 \%$ of lesions tends to become more prominent in late childhood, but at this stage the nevus becomes paler. Malignant neuroectodermal tumours and malignant melanoma might develop in the lesions of a giant congenital melanocytic nevus. Bathing trunk nevus may also be associated with several conditions like neurocutaneous melanosis, diffuse lipomatosis, von-Recklinghausen's disease, vitiligo, structural brain malformations, hypertrophy of skull bones and skeletal asymmetry. We are here with reporting one case of bathing trunk nevus in a female patient.[1-4]

\section{DIFFERENTIAL DIAGNOSIS}

Café-au-lait macule, congenital melanocytic nevus, dermal melanocytosis, Ecchymosis, Epidermal nevus.

\section{CLINICAL DIAGNOSIS}

The lesions on the body are large, circumferentially pigmented area in front of neck, spread to chest, abdomen to thighs and up to knees as well as same spread to back of body bilaterally interposed darkened lesions were present. Asymptomatic, hyperpigmented, encompassing the entire trunk involving chest, back, buttocks and genitalia covering more than $40 \%$ of body area present since birth. It has been growing in size with age. The lesions were flat initially and gradually started becoming thicker. Scalp, mucosa, palms, soles and nails were normal. This is a typical case of giant congenital melanocytic nevus (Figures: 1-6).

\section{PATHOLOGICAL DISCUSSION}

Patients with large or CMN also have a $10 \%$ incidence of neurocutaneous melanosis (NCM), a rare congenital syndrome that present with multiple CMN and melanocytic tumour cells in the central nervous system, specifically on the leptomeninges, arachnoid and pia mater. Neurocutaneous melanosis is more frequent if the nevi are found on the spine, head or neck. The tumours cause increased intracranial pressure with initial presentation of seizures, hydrocephalus or other neurologic symptoms depending on the degree of spinal cord compression. The melanocytic tumour cells also carry a $40 \%$ to $60 \%$ prevalence of melanoma progression. In patients with large or giant $\mathrm{CMN}$, magnetic resonance imaging of the brain and spine is sufficient to determine neurologic involvement. Magnetic resonance imaging is the test of choice, because the paramagnetic effect of melanin lead to a decrease in both $\mathrm{T} 1$ and $\mathrm{T} 2$ relaxation times. Neurologic involvement has a highly characteristic appearance with the most common finding being $\mathrm{T} 1$ shortening in the cerebellum, temporal lobes, pons and medulla. Knowledge of these locations help to differentiate melanotic deposits that are characteristic of NCM from 
metastases secondary to malignant degeneration of a large or giant CMN. Patients with NCM have a poor prognosis, as they usually die within the first year of life.[2]

\section{DISCUSSION OF MANAGEMENT}

Large or giant CMN without neurologic involvement primarily is removal of the lesion, which usually occurs when the patient is 6 months or older, as there is less risk associated with anaesthesia, but before puberty when the risk for malignancy increases. Because of the size of these large nevi, treatment has proved to be more difficult than originally thought. Some surgical techniques have been used with success including serial excision with skin grafts, skin flaps, tissue expansion or artificial skin replacement. An emerging therapy involves the use of dermal regeneration template followed by split-thickness graft after stable integration of the dermal matrix. Some lesions are too large or potentially deforming to fully remove and they must be carefully monitored. Alternative treatments include phenol chemical peels, dermabrasion and laser therapies for lesions that cannot be surgically treated but cosmesis is desired. These techniques, however, do not demonstrate complete destruction of the nevus cells. There have been studies with normal-mode ruby laser and Q-switched alexandrite laser treatments as well as curettage followed by erbium: YAG laser ablation. Each of these treatments demonstrated reduced pigmentation and improvement in colour and cosmetic appearance. A full discussion of these treatments and their associated risks and benefits is beyond the scope of this article. Chronological photographs are useful to compare lesions over time and to guide biopsies. Most dermatologists follow up with patients with CMN every 6 months and approaching lesions aggressively.[1-5]

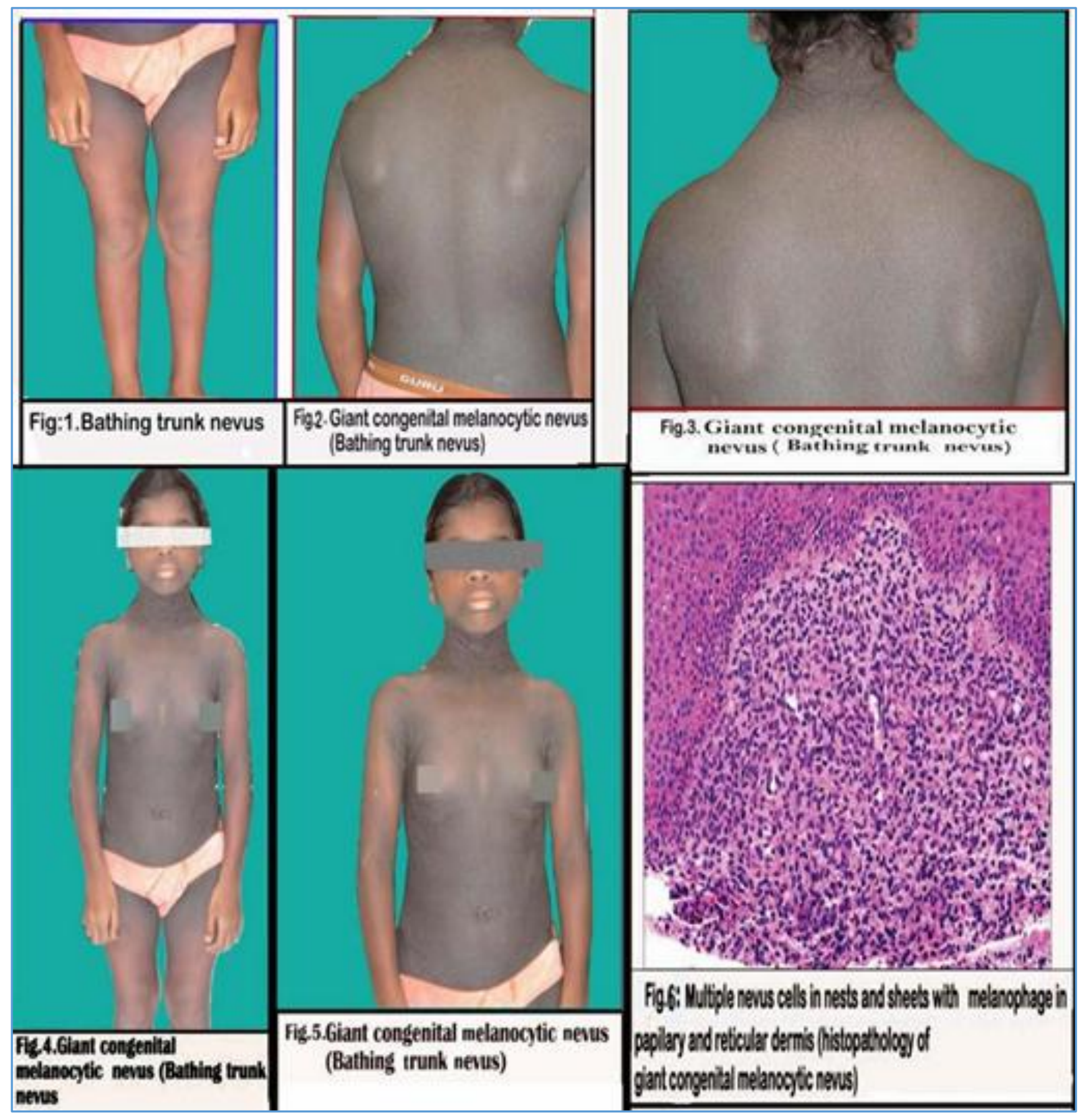




\section{FINAL DIAGNOSIS}

Asymptomatic hyperpigmented nevus encompassing the entire trunk involving chest, back, buttocks and genitalia covering more than $40 \%$ of body area present since birth. It has been growing in size with age. The lesions were flat initially. After considering all the circumstances above, the thirteen years old female patient was diagnosed as having Giant congenital melanocytic nevus or Bathing Trunk Nevus.[1-14]

\section{REFERENCES}

[1] Bhagwat PV, Tophakhane RS, Shashikumar BM, et al. Giant congenital melaonocytic nevus (bathing trunk nevus) associated with lipoma and neurofibroma: report of 2 cases. Indian J Dermatol Venereol Leprol 2009;75(5):495-8.

[2] Russ R, Light L. Bathing trunk nevus: case report of giant congenital melanocytic nevus. Cutis 2009;83(2):69-72.

[3] Hoffman D, Ratner D. Diagnosis and management of a changing congenital melanocytic nevus. Skinmed 2006;5(5):242-5.

[4] Pielop JA. Vascular lesions and congenital nevi in the newborn. Accessed March 19, 2007. http://www.patients.uptodate.com/topic.asp?file=ped _derm/4439\&title=Congenital+nevi. html.

[5] Pearson GD, Gomuwka PK. Skin, congenital hairy nevi. Emedicine Accessed March 19, 2007. htttp://emedicine.medscape.com/article/1295033overview.
[6] Watt AJ, Kostis SV, Chung KC. Risk of melanoma arising in large congenital melanocytic nevi: a systemic review. Plast Reconstr Surg 2004;113(7):1968-74.

[7] Russell JL, Reyes RG. Giant pigmented nevi. J Am Med Assoc 1959;171:2083-6.

[8] Cabrera H, Gomez ML, Garcia S. Lipomatous melanocytic nevomatosis. J Eur Acad Dermatol Venereol 2002;16(4):377-9.

[9] McKie RM. Disorders of the cutaneous melanocyte. In: Burns T, Breathnach S, Cox N, et al. eds. Rook's Textbook of Dermatology. $7^{\text {th }}$ edn. London: Blackwell Science 2004;38:18-38.

[10] Chung C, Forte AJ, Narayan D, et al. Giant nevi: a review. J Craniofacial Surgery 2006;17(6):1210-5.

[11] Ansarin H, Soltani-Arabshahi R, Mehregan D, et al. Giant congenital melanocytic nevus with neurofibroma-like changes and spina bifida occulta. Int J Dermatol 2006;45(11):1347-50.

[12] Ahuja SR, Karande S, Kulakarni MV. Multiple giant congenital melanocytic nevi with central nervous system melanosis: a case report. Neurology India 2003;51(4):541-3.

[13] Gorai S, Saha M, Seth J. Giant congenital melanocytic nevus with occipital encephalocele: a very rare association. Indian J Dermatol 2016;61(2):224-6. http://www.eijd.org/text.asp?

[14] Sharma S, Sharma N, Sharma V. Giant bathing trunk nevus with multiple congenital melanocytic naevi. The Internet Journal of Pediatrics and Neonatology 2012;14(1):1-5. 